\title{
The Global Positioning System
}

The Global Positioning System (GPS) is a constellation of navigation satellites called Navigation Satellite Timing And Ranging (NAVSTAR), maintained by the U.S. Department of Defense. Many outdoor enthusiasts recognize that a handheld GPS receiver can be an accurate tool for determining their location on the terrain. The GPS receiver helps determine locations on the Earth's surface by collecting signals from three or more satellites through a process called triangulation. Identifying a location on the Earth is more useful if you also know about the surrounding topographic conditions. Using a topographic map with the GPS receiver provides important information about features of the surrounding terrain and can help you plot an effective route from one location to another.

\section{Using Topographic Maps With the GPS}

When using a topographic map with a GPS receiver, you need to ensure that the receiver has been programmed correctly to account for variables such as the map datum, coordinate system, and units of measure. Refer to the instructions that accompany the specific receiver being used to ensure that these variables are entered correctly. Most USGS maps were compiled using the North American Datum of 1927 (NAD27), although recently revised maps use the North American Datum of 1983 (NAD83). You will need to refer to the map compilation notes in the lower left corner of each map to determine the correct datum to enter into the GPS setup program. You will also need to program the GPS receiver to use the correct coordinate system, either Universal

Transverse Mercator (UTM) or Latitude/Longitude. When using the UTM coordinate system, be sure to program the correct UTM zone into the setup parameters of the GPS receiver. The UTM zone information is found in the map compilation notes for each map. The desired units of measure (meters or feet) will also need to be entered into the setup parameters. You should select meters when using the UTM coordinate system to ensure compatibility between the two parameters.

\section{Topographic Map Tools}

Both the UTM and the Latitude/Longitude coordinate systems allow GPS positions to be plotted on a map and map positions to be entered into the GPS. The USGS publishes coordinate reading tools that make it easier to determine coordinate positions.

The Metric Coordinate Reader is a tool used for determining points or positions on maps that have a metric grid, such as the UTM grid. The CR-1 version is designed for use on maps with scales of 1:50,000, 1:100,000, 1:250,000, 1:500,000, and 1:1,000,000, whereas the CR-2 version is designed for use on maps with scales of 1:24,000, 1:25,000, $1: 62,500,1: 125,000$, and 1:250,000. Some USGS maps do not depict the complete printed UTM grid, but you can construct a grid by drawing lines that connect blue UTM ticks found in the margins of the map. When a full grid is carefully drawn, metric coordinates of map points can be measured directly with the reader. Both metric coordinate readers come with instructions and cost $\$ 2.50$ each, plus a $\$ 3.50$ handling charge.

The Latitude and Longitude Reader can be used to interpolate this coordinate system on USGS 7.5-minute topographic maps. This tool is designed for use with maps whose latitudes fall between 10 degrees and 50 degrees, and it allows for the convergence of the lines of longitude at the higher latitudes. To use this reader, draw a grid on the map at an interval of 2 minutes and 30 seconds, using the ticks found in the margin of the map. After carefully drawing the grid, you can use the reader to directly measure the latitude and longitude coordinates of map points. The latitude/longitude reader comes with instructions and cost $\$ 2.00$, plus a $\$ 3.50$ handling charge.

The above coordinate reading tools can be obtained by contacting the USGS at:

U.S. Geological Survey

507 National Center

Reston, VA 20192

1-888-ASK-USGS

\section{GPS Accuracy Considerations}

Several things must be taken into account when determining the accuracy of handheld GPS receiver readings.

\section{Stand-Alone mode of operation}

A GPS receiver used in a stand-alone (handheld) mode can provide accuracies within $+/-100$ meters of a true position. Such variations in accuracy can be attributed to one or more of the following factors:

Selective availability (S/A) is the intentional degradation of the GPS signal. The Department of Defense controls S/A to limit accuracy for non-U.S. military users. S/A can introduce errors of up to 100 meters.

User mistakes, including incorrect geodetic datum selection, can cause errors from one to hundreds of meters. The user should always be certain to select the datum that corresponds with the map being used.

Receiver errors from software or hardware failures can cause errors of any size.

Map error on USGS topographic maps can be $+/-12.2$ meters at the 1:24,000 scale as determined by National Map Accuracy Standards. This factor should be taken into account when comparing GPS readings to a topographic map. 


\section{Additional Information Sources}

\section{Publications}

USGS Fact Sheet 142-97 - The Universal Transverse Mercator (UTM) Grid - Covers topics on map projections, the UTM grid, and determining a UTM grid value for a map point (Free).

USGS Topographic Map Symbols - A pamphlet that depicts and describes the symbols used on USGS topographic maps (Free).

USGS Fact Sheet 122-95 - Digital Raster Graphics - Provides information on the USGS digital raster graphic (DRG). A DRG is a scanned image of a USGS topographic map. The image is georeferenced to the Earth in the UTM coordinate system, which makes it ideal for use with GPS receivers.

The above USGS publications are available from:

USGS Information Services

Box 25286

Denver, CO 80225

1-888-ASK-USGS

\section{Internet Sites}

You can find information on GPS resources by doing keyword searches using one of the many Internet search engines available. Shown below are some of these search engines and their Internet addresses:

AltaVista - http://www.altavista.com/ Yahoo - http://www.yahoo.com/ Lycos - http://www.lycos.com WebCrawler - http://www.webcrawler.com/ MonkeySweat -

http://www.MonkeySweat.com

The following Internet sites have been found to be very useful:

The U.S. National Geodetic Survey Principal U.S. Government agency responsible for providing geodetic resources, products, and services. Site contains access to survey monument control data sheets and coordinate conversion software.

http://www.ngs.noaa.gov/
U.S. Coast Guard Navigation Center - Site contains GPS satellite almanac and orbit information.

http://www.navcen.uscg.mil/links/

National Geographic Maps - Trails Illustrated - Tutorials describing the use of GPS with topographic maps.

http://www.trailsillustrated.com/topotalk.cfm

Macintosh GPS Communications-The Global Positioning System (GPS) Library - Site contains numerous links to GPS-related Web sites.

http://www.gpsy.com/gpsinfo/

\section{Information}

For information on other USGS products and services, call 1-888-ASK-USGS, use the EARTHFAX fax-on-demand system, which is available 24 hours a day at 703-648-4888, or visit the general interest publications website at http://mapping.usgs.gov/mac/isb/pubs/ pubslists/index.html.

Please visit the USGS home page at http://www.usgs.gov/. 